\title{
HISTÓRIA E MEMÓRIA DA “EDUCAÇÃO FÍSICA” NA EDUCAÇÃO INFANTIL"
}

\author{
Ana Cristina ARANTES ${ }^{*}$ \\ Elizabete CRUZ \\ Angélica V. da HORA \\ Nathália C. CARDOSO
}

\section{APRESENTAÇÃo}

$\mathrm{O}$ artigo preparado para este tutorial, visa informar o leitor sobre algumas concepçð̃es acerca da infância praticados em diferentes épocas e classes sociais. Também discutirá sobre as atividades motoras, já que o movimento é uma característica fundamental dos seres vivos. $\mathrm{O}$ possível cotidiano / currículo (e particularmente as atividades motoras), das instituiçð̃es .formais e não formais também serão incluídas, pois a partir deste - leitor poderá conhecer as políticas de atendimento implementadas as crianças brasileiras até a década de $\mathbf{4 0}$ do século passado.

Este artigo pode ser considerado como uma revisão de literatura, com tratamento descritivo qualitativo das informações obtidas pelo grupo de pesquisadoras.

\section{As primeiras idéias e recomendações sobre o movimento e as crianças}

Historicamente falando, o movimento considerado como uma atividade humana muito importante, tem recebido atenção por inúmeros estudiosos desde a mais antiga civilização. Praticado por crianças e citado desde a Antigüidade grega sob a forma de jogo $e$ de ginástica, favorece não somente a formação do aspecto motor mas também segundo vários autores, parece contribuir para a construção de um homem íntegro e hígido como explicita Jaeger, (1994) em seu livro Paidéia: a formação do homem grego.

Guardadas as devidas proporçð̃es (e classes sociais) e estabelecendo um paralelo entre $o$ legislador e o ginasta, o autor citado afirma que os (seus) "ofícios se ocupam respectivamente da alma e do corpo são tal como o juiz e o médico que se ocupam respectivamente, por sua vez, da alma e do corpo doentes" (p.796).

Os exercícios ginásticos sob a responsabilidade do pedótriba, devem cuidar do corpo físico - entretanto - recomenda-se que os praticantes para a sua melhor formação recebam também a contribuição formativa da música.

Segundo pensamento da época, este elemento estético alimenta e enobrece a alma, fornecendo ao educando valores catárticos evitando assim, a instalação da doença naquele que se exercita. "A sinfonia da alma é o resultado de uma combinação acertada de dois elementos a música e a ginástica" (p.810).

Ainda que o autor não se refira a que classe social se reporta ou a quem dirige as suas palavras, presume-se que retrate a elite pois esta social sempre representou os ideais de perfeição humanos. Por conseguinte, as outras classes, ao que tudo indica, não mereceram tratamento semelhante. Assim sendo, o movimento, a música e a ginástica, somados a instrução ou a educação formal, deveriam estar vinculadas a vida das pessoas (nobres) desde a mais tenra idade.

No sentido de contribuir para uma ótima formação dos indivíduos Platão recomendava caminhadas às gestantes pois, segundo o filósofo, "havia necessidade do movimento mesmo antes da criança nascer. Mais adiante observava que " os balanços do corpo com ou sem esforço próprio, exercem sobre 0 homem uma ação revigorante como acontece com o passeio, com o balanço, com os cruzeiros por mar, a equitação e outros tipos de movimento" (p.13.50).

Escola de Educação Física e Esporte da Universidade de São Paulo. 
Após o nascimento e ainda na fase de amamentação, o autor da República recomenda que as mães devem massagear seus filhos oferecendo a estes o que hoje corresponderia a noção próprioceptiva.

Em continuidade, o autor afirma que o movimento é algo inerente ao ser em desenvolvimento" e (que) "de modo nenhum devese obrigá-las (as crianças) a permanecerem quietas. Isso é contrário a natureza da criança que, a rigor, deveria mover-se...pois o movimento exterior liberta-a do medo interior e a sossega" (p.1351).

Quanto ao desenvolvimento humano compreendido entre três aos seis anos, e no tocante a relação ensino aprendizagem Kishimoto (1994) e Jaeger (1994), concordam que este deve ser realizado de maneira lúdica e sob a forma coeducativa. Praticado em espaço aberto, (e sagrado), deveria ser apropriado por todos os participantes da comunidade. As regras dos jogos, por sua vez, deveriam ser construídas pelos próprios membros do grupo cabendo às senhoras designadas pelo governo, a tarefa de supervisionar a atividade sem entretanto, direcioná-la ou alterar a sua essência: "Nesta idade, são as crianças quando se juntam, que devem inventar seus jogos, sem que estes lhe sejam prescritos" (p.1353).

O movimento entendido como uma atividade inerente a infância, pelo seu alto valor educacional, precisa ser exercitada desde a mais tenra idade (Arantes, 1996/1998).

$$
\text { primeiro, a idade dos }
$$

brinquedos: as crianças brincam com um cavalo de pau uma boneca, um pequeno moinho ou pássaros amarrados. Depois, a idade da escola: os meninos aprendem a ler ou seguram um livro e um estojo; as meninas aprendem a fiar. Em seguida , as idades do amor ou dos esportes (sic) da corte e da cavalaria: festas, passeios de rapazes e moças, cortes de amor, as bodas ou a caçada do mês de maio dos calendários (Ariès, 1978, p.39).

Embora a infância (e a juventude) seja caracterizada como uma fase possuidora de vigor e de virtude, a idéia que se tinha sobre o primeiro período de vida não descartava a idéia de dependência. Deixava-se de ser criança apenas quando se galgava a independência ainda que de forma precária. Como as necessidades infantis inclusive no tocante as aspirações das classes sociais, eram desconhecidas e, como também talvez não houvesse distinção tarefa, tanto as da plebe, como as legítimas e as bastardas eram no século XVII tratadas igualmente como qualquer criança nobre.

esse menino de quatro a cinco anos praticava o arco, jogava cartas e xadrez (aos seis anos) e participava de jogo de adultos, como o jogo de raquetes e inúmeros jogos de salão.... ele dança apenas os balés ou as danças da corte que aprende com um professor, assim como aprende a leitura e a escrita. Participavam também do que hoje chamamos de danças populares (Ariès, 1978, p.86)

No século XVII entretanto, esta maneira de pensar foi alterada ainda que de forma rudimentar. Mas somente no Século XVIII mais precisamente na figura de Rousseau que a criança deixa de ser um ser desprezível, destituída de alma ou ainda de ser considerada como um adulto em miniatura.

Durante muitos séculos, aos sete anos, a criança abandonando os trajes infantis e a educação familiar, era entregue aos cuidados dos homens assim expressando "um pouco mais de bonecas $e$ de brinquedos alemães antes dos sete anos, um pouco mais de caça, de cavalos armas $e$ talvez teatro após essa idade" (Ariès, 1978, p.878).

Quanto as atividades praticadas por crianças e adultos durante séculos não havia separação rigorosa tal como ocorre hoje. Os mesmos jogos eram comuns a ambos. As brincadeiras infantis não tiveram outra origem senão aquela de imitar o adulto (jogo simbólico). A mesma ausência de distinção de objetos por gênero dava-se nos brinquedos usados por meninas e por meninos fato este alterado no século XV.

A prática das atividades físicas para a nobreza - a cavalaria é vista como uma prática distinta das demais classes sociais.

Como o trabalho adulto, provavelmente $o$ trabalhador do campo, não ocupava todo o tempo dos homens, o jogo de bola reunia várias comunidades numa ação coletiva. Embora haja aqueles que na Idade Média considerem esta prática gratuita, condenem os jogos de azar, os de salão, a comédia e a dança, por exemplo (Ariès, 1978), o divertimento e a ludicidade pode ser vista como muito valorizada pelos seguidores do Atomismo (Lauand ${ }^{2}$ ). 
As atividades infantis entretanto, estavam restritas e imitavam aquelas realizadas pelos adultos.

\section{O período da Renascença}

Oliveira (1983, p.36)

O período Renascentista, segundo

representou uma nova concepção do mundo e do homem, havendo um redescobrimento da individualidade, do espírito crítico e da liberdade do ser humano" Em continuidade afirma que "o reconhecimento destes traços de individualidade devolveu à criatura humana o papel de protagonista; é o antropocentrismo em oposição ao teocentrismo medieval. Inspirado nas obras da Antigüidade clássica esse humanismo renascente voltou a valorizar o belo, resgatando a importância do corpo. A Educação Física torna a ser assunto dos intelectuais numa tentativa de reintegração do físico e do estético às preocupações educacionais.

Segundo o autor citado, quanto a prática dos exercícios físicos a ser implementada nas escolas para as crianças da elite e maiores de sete anos, deveria compor-se de passeios, jogos, natação, equitação, exercícios corporais e o manejo das armas. Somados aos saltos, corrida, luta, jogo de pelota e a dança. constituíam o currículo da educação cortesã.

Para Feltre, pedagogo renascentista, de acordo com Bononino (1931), as práticas ginásticas, os jogos, a esgrima, a natação a equitação as marchas longas a resistência ao frio e ao calor; enfim todos os exercícios e as atividades que desenvolvessem as faculdades fisicas $e$ as energias morais do homem, eram consideradas como meios educativos destinados às crianças e aos jovens. Estas atividades tornavam-se complexas a medida em que os educandos cresciam. Assim sendo, às primeiras somavam-se o lançamentos com flechas, o manejo das espadas e as atividades com bola.

Antes disto, porém "não de deve ser exercitados o organismo infantil antes dos cinco anos pôr que é ainda muito novo e que só depois daquela idade, deveriam ter inicio os exercícios, levando - se em conta a fragilidade daquele organismo" (Nunes, 1980).

Em continuidade escreve sobre os exercícios físicos para os jovens afirmando quereles os jovens devem ser exercitados para afugentar a preguiça do corpo. Devem execitá-los convenientemente pôr meio de jogos que não devem ser muito brandos, nem muito fatigantes, mas sobretudo nunca ser indignos de um homem livre"

\section{Outros estudiosos e concepções}

Basedow um outro estudioso do período renascentista escreveu três volumes (Livro elementar) destinados a educação. Neles à Educação Física confere-se um importante papel no processo de educação global não devendo ser percebida "como algo complementar mas como uma real contribuição no processo de crescimento $e$ de desenvolvimento de todas as pessoas" (Bononino, 1931, p.77).

Para Rousseau, a educação antes de mais nada deveria formar o homem. Para tanto, a prática dos exercícios físicos, a alimentação pura e sadia e 0 arejamento do ambiente, poderia constituir-se em elementos importante à saúde e ao desenvolvimento corporal. "cultivai a inteligência de vossos alunos, mas cultivai antes de tudo, o seu fisico por que é ele que vai orientar o desenvolvimento intelectual; fazei primeiro vosso aluno são e forte para podê-lo ver inteligente $e$ sábio" (Bononino, 1931, p.77).

Pestallozzi, continuador da obra de Rousseau também reconhece que é "da construção fisica do corpo humano e seus movimentos naturais é que devem surgir as bases pedagógicas $e$ fisiológicas donde promarão os principios reguladores dos exercícios e da ginástica" (Monroe, 1931, p.78).

Assim sendo, para Pestalozzi tanto quanto para Rousseau e Froebel - o pai do Jardim de Infância na Alemanha, como explicita Nicolau (1989)

o desenvolvimento é orgânico sendo que a criança se desenvolve pôr leis definidas os poderes infantis britam de dentro para fora; os poderes inatos, uma vez despertados, lutam para se desenvolver até a maturidade: a gradação deve ser respeitada; o método deve seguir a natureza; o 
professor é comparado a um jardineiro que providencia as condições para a planta crescer a impressão sensorial é fundamental e os sentidos deve estar em contato direto com os objetos; a mente viva (p. 29).

Em se tratando de uma exposição histórica, Bacon outro importante nome da intelectualidade, defendia a execução de exercícios naturais, tendo estudado a manutenção orgânica e o desenvolvimento físico sob o prisma filosófico. Locke, por sua vez, recomendava a prática da "educação física" aconselhando também que as crianças fossem sujeitas a um regime de vida bastante rigoroso - o regime a que se refere significava condição essencial para a manutenção da saúde.

Até o final do século XVIII crianças e jovens praticavam as mesmas atividades mas a literatura pesquisada com grande frequiência se reporta somente a infância privilegiada; isto significa que a criança pobre $e$ a infância marginalizada não mereceu atendimento semelhante aos da elite econômica. Isto ocorreu muito posteriormente e, no Brasil ,com os filhos da classe operária deu-se apenas nos anos 30 do século passado.

A infância como objeto de preocupação e de estudo só se "fixa" a partir do final do século XVIII quando a burguesia reclama para si valores e bens que eram até então, restritos a elite econômica. Entretanto, segundo Faria (1993) não se pode falar em um reconhecimento generalizado da sua identidade. A criança se emancipa lentamente.

Assim entendendo desde o final do século XVIII, as crianças burguesas começavam a ter escola, professores brinquedos, livros enquanto a proletária continua a viver uma condição de vida adulta, com as pessoas grandes da sua família e do ambiente extra doméstico (Becchi, 1983).

\section{$\mathbf{O}$ atendimento à criança brasileira}

Nos séculos passados, na tentativa de se organizar o corpo brasileiro, alguns estudiosos publicaram livros destinados em última análise à melhoria da raça. Apesar das muitas recomendações feitas a população, às crianças brasileiras, particularmente aquelas de origem economicamente desfavorecida, não receberam tratamento recomendado e necessário. Ainda que o asseio corporal e a higiene fossem alardeados como necessários ao indivíduo os preceitos serviram a objetivos diferentes e também seguiam os preceitos imaginados pelas diferentes classes sociais.

$O$ direito a infância e a educação entendendo o termo educação como algo mais amplo que o processo de escolarização, quase sempre procurou estar a serviço das demandas e das necessidades das novas gerações. - atendendo apenas a interesses específicos de um determinado grupo - o dos burgueses.

Até a promulgação da Lei do Ventre Livre a crianças eram criadas juntas e amamentadas pela ama de leite. Após este período e particularmente com a instituição da República e o trabalho fora de casa, muitas mulheres viram a sua prole desassistida.

Àquelas filhas de mães trabalhadoras foram criadas as creches cujo trabalho restringia-se a assistência e a formação de hábitos de saúde. Os locais de abrigo eram distantes e denominados asilos.

\section{Quanto a educação formal a elite}

Para os da elite entretanto, foram criados nos centros urbanos que de desenvolviam os Jardins de Infância calcados nos currículos de Froebel (Arantes, 1998).

O Jardim de Infância destinava-se às crianças bem - nascidas da elite paulistana. Cercada de muito carinho e professoras competentes tinham aquilo que se julgava ser $o$ mais interessante para elas. Segundo Kulmann Júnior $(2000, \mathrm{p} .67)$ "a programação das atividades, composta de exercícios de linguagem, dons froebelianos, trabalhos manuais, modelagem $e$ desenho, números, cores, música ginástica $e$ brinquedos"

Em uma versão livre pode-se afirmar que, no século dezenove, estudiosos inspirados no valores da Grécia Antiga, reconheceram reavaliaram as questões relativas a educação formal ao movimento e ao jogo: "O brinquedo será em todos os tempos a primeira e única occupação da infância, bem como a mais prazenteira, nos outros periodos da vida."

A "Revista Jardim de Infância" (1897), destinada às professoras do Jardim de Infância da Praça da República em São Paulo, escrevendo sobre o trabalho, define- o como destino comum da humanidade, desde que o mesmo satisfaça as propulsoras necessidades da 
vida. Em continuidade, escreve que, tudo, o mais é brinquedo - ou (apenas) recreio corporal $e$ espiritual.

O brinquedo infantil também parece assumir o mesmo caráter de uma prática necessária e significativa ao desenvolvimento humano. Para Salles de Oliveira (1986), é considerado como uma ocupação séria. Significa a exteriorização e expressão da totalidade do ser humano Por conseguinte, suprimir a criança (pensante) dos brinquedos e dos jogos adaptados e supervisionados, (ou não), é desconsiderar suas necessidades motoras, psíquicas e intelectuais.

$O$ ato de brincar deve ter por meta 0 "desenvolvimento da força física, concorrer para - aperfeiçoamento dos instrumentos da alma humana - os sentidos $e$ desenvolver os sentimentos dando-lhes uma direção" (p.208).

Inspirados nos idéias de Froebel o

jogo e o brinquedo no século XIX eram classificados como (a) aqueles exercitam o corpo. "Os jogos do corpo, os brinquedos de movimento, exercitam a força physica, e a habilidade do corpo; são a verdadeira expressão de alegria $e$ gozo" os destinados ao desenvolvimento dos (b) sentidos. Os brinquedos que miram a educação dos sentidos são os que exercitam a vista (sic), o ouvido, o tacto, o gosto e o olfacto. Atualmente, corresponderiam aos jogos sensoriais os aqueles denominados "jogos de volta à calma". Assume-se que existe um terceiro grupo formado pelas atividades que exercitam 0 espírito. " $O s$ brinquedos espirituais, (segundo o texto), são occupações que multiplicam as instituições, desenvolvem a intelligência, a atenção, $a$ observação e fortificam (sic) a memória" (p.209).

Balizado pelos preceitos da orientação romântica, os inspiradores do Jardim de Infância acreditavam que os brinquedos acalmavam as más tendências e favoreciam o desenvolvimento das boas inclinações humanas e como tal pode ser apreciado nas frases:

a criança tende para a luz ... os jogos sãa, na maior parte, executados em um ambiente onde a luz domina soberana, vivificando com seus brilhantes raios.

Tomando por base a recomendação de Froebel, as atividades motoras deveriam ser realizadas em um ambiente saudável de maneira agradável e lúdica.
Na Escola Caetano de Campos em São Paulo, as aulas de ginástica praticadas pelos filhos da elite, duravam em média oito minutos. Duas a três vezes por semana, exercícios de ordem unida, marcha, (evoluçð̃es e infiltraçð̃es, com ou sem material), eram realizadas pelas crianças ao lar livre - em espaços abertos. Somada a esta, realizada no início da aula, havia os exercícios ginásticos, executados de forma analítica e individual e os jogos praticados de forma supervisionada pela "maestra jardineira" Estes últimos por sua vez na páginas subsequentes explicita que "quando acompanhados pelo canto, favorecem $e$ desenvolvem essa tendência gentil. que tanto poder educativo tem sobre a alma humana" e mais fomentam a tendência gregária que a criança apresenta o autor explicita que "os jogos em sociedade contentam-n'a quanto a sua disposição" (Revista Jardim de Infância, 1897, p.210-1).

Segundo o texto estudado, os jogos pela sua característica e essência, parecem atender as demandas do pré-escolar e, nos períodos iniciais, ao que os dados nos levam, a inferir serem atividades muitas vezes realizadas "lado a lado" o que de certa forma respeitam as características infantis. Posteriormente, gradativamente e respeitando os Periodos, (divisão das classes de acordo com as idade cronológica), virão as regras tornando a atividade mais complexa, ampliando as relações sociais.

No Jardim de Infância da Praça da República, no início do século passado, os jogos praticados pelas crianças da elite, sem alterar a característica de individualidade, criarão gradativamente hábitos necessários á sua vida futura. Isto significa que as atividades, por elas praticadas paulatinamente, deveriam tornar-se mais complexas. A inclusão de regras estava prevista pelo docente e deveria adequar -se aos interesses infantis. Estas atividades provavelmente cumpriam um dos objetivos da escola froebeliana, qual seja a socialização das crianças.

$\mathrm{Na}$ educação formal, os brinquedos e (os jogos), implementados pela professora jardineira. Representariam a vida, os costumes infantis transmitidos por tradição e repetição através dos séculos, além disso, representam um meio que influencia a educação moral e social.

Os poucos jogos de "movimento"(quando haviam), realizados nos asilos de crianças, ao contrário daqueles implementados no Jardim de Infância da Escola 
Caetano de Campos, eram realizados em ambientes inadequados e limitavam-se ao desenvolvimento da força física. Admoestando o leitor desavisado, o estudioso ainda escreve "Enganam-se os que acreditam serem taes jogos apenas exercícios gynmasticos" (p.223).

\section{Os novos tempos e a nova oportunidade}

Entretanto, com o passar do tempo e com a mudança da mentalidade, as exigências impostas pelos cidadãos, as oportunidades educacionais foram sendo ampliadas. Assim sendo, a partir de 1920, e, particularmente os anos 30 as transformações sociais são muito significativas. As correntes migratórias e 0 processo de imigração parecem ter contribuído para a formação de uma nova maneira de agir e de pensar dos paulistanos. A partir das novas demandas sociais, e tendo como figura de síntese o nome de Mário de Andrade criam-se novos serviços destinados aos brasileiros de pouca idade pertencentes a classe operária. Um destes serviços - os Parques Infantis foram implementados na tentativa de oferecer uma programação que visasse a apropriação da cultura brasileira. Estruturado a partir de uma mão de obra de especificidade nascente, buscou atender a criança tanto nos aspectos particulares como inserindo-a em um contexto macro estrutural - a de um brasileiro. Para tanto o escritor de Macunaíma valeu-se da arte, das danças regionais e das atividades recreativas e dos jogos populares.

As sessões de Educação Física eram destinadas ao desenvolvimento de aspectos de ordem física, ao aumento progressivo da coordenação motora da criatividade às descargas da agressividade e à socialização. Tudo era feito em valendo-se da recreação, visando ao desenvolvimento físico, intelectual $e$ sócioemocional da criança. Este projeto de tão pouca duração pretendia favorecer a implementação viva dos costumes nacionais. além de mais uma vez auxiliar a veiculação dos hábitos de saúde e de higiene. Entretanto, poucos entenderam a Mário e ao Projeto dos Parques.

$\mathrm{Da}$ instituição (não formal) de educação popular, embora seja reconhecida como um serviço muito importante no atendimento das classes menos favorecidas quase nada restou. Embora tendo servido inclusive de parâmetro para a concepção dos currículos das Escolas Municipais de Educação Infantil seus fundamentos e as suas propostas foram paulatinamente abandonadas em nome talvez de uma escolarização de cunho erudito. Embora a criança escolar do século XXI pratique as atividades motoras tais como a dança, 0 jogo, a luta, "ginástica e esporte" conteúdos das educação física atual ao que os dados indicam, nem sempre tem alcançado os seus objetivos, nem sempre são realizadas com a devida competência e o luder magister que reuna todos os quesitos necessário à formação integral do ser humano parece estar sendo necessário ser revivido e avaliado.

\section{NOTAS}

1. Tutorial "História e memória da educação física na educação infantil"

2. LAUAND. J. O lúdico no pensamento de Tomás de Aquino e na pedagogia medieval. Conferência proferida no Curso de extensão cultural Cinema e Idade Média. Realizada na Universidade de São Paulo, 2001.

\section{REFERÊNCIAS BIBLIOGRÁFICAS}

ARANTES, A.C. A educação física e a educação infantil: um estudo inicial e primeiras impressões acerca desta atividade na transição de Brasil Monárquico e República. 1997. In: CONGRESSO DE HISTÓRIA DA EDUCAÇÃO FÍSICA, DO LAZER E DO ESPORTE, Belo Horizonte, 1996. Anais. Belo Horizonte, 1996. p.-114-9.

ARIĖS, P. História social da criança e da família. Rio de Janeiro, Guanabara, 1978.

BECCHI, E. Molte infanzia, poche storie. Ricerche pedaoggiche, n.68-9, p.1-15, 1983.

BONONINO, L.L. Histórico da educação física. Futura, Imprensa Oficial, 1931.

FARIA, A.L. Direito à infância: Mário de Andrade e os parques infantis para a criança de família operária na cidade de São Paulo (1935-1938). São Paulo, 1993. 200p. Tese (Doutorado) - Faculdade de Educação da Universidade de São Paulo.

JAEGER, W.W. Paidéia: a formação do homem grego. 3.ed. São Paulo, Martins Fontes, 1994. p.795-1373.

KISHIMOTO, T.M. O jogo e a educação infantil. São Paulo, Pioneira. 1994.

KULMANN JÚNIOR, I. Histórias da educação infantil brasileira. Revista Brasileira de Educação, n.14, p.5-17, 2000. Número especial: 500 anos de educação escolar.

MONROE, P. História da educação. 6.ed. São Paulo, Nacional, 1958.

NICOLAU, M.L.M. A educação pré-escolar: fundamentos e didática. São Paulo, Ática, 1989. 
NUNES, R.A. História da educação no Renascimento. São Paulo, EPU, 1980.

OLIVEIRA, V.M. O que é educação física? 2.ed. São Paulo, Brasiliense, 1983.
REVISTA DO JARDIM DE INFÂNCIA: Dos jogos nos jardins da infância. São Paulo, v.3, p.206-25, 1897.

SALLES DE OLIVEIRA, S.P. O que é brinquedo. São Paulo, Brasiliense. 1986.

ENDEREÇO: Ana Cristina Arantes

Departamento de Pedagogia do Movimento Humano Escola de Educação Física e Esporte -USP

Av. Prof. Mello Moraes, 65

05508-900 - São Paulo - SP - BRASIL 